\title{
A field study of thermal comfort in low-income dwellings in England before and after energy efficient refurbishment
}

\author{
Sung H. Hong ${ }^{\text {a, }}$, Jan Gilbertson ${ }^{b}$, Tadj Oreszczyn ${ }^{a}$, Geoff Green ${ }^{b}$, \\ Ian Ridley ${ }^{a}$, the Warm Front Study Group ${ }^{c}$
}

a The Bartlett School of Graduate Studies, University College London, Gower Street, London, WC1E 6BT, UK

${ }^{b}$ The Centre for Regional Economic and Social Research (CRESR), Sheffield Hallam University, City Campus, Howard Street, Sheffield, S1 1WB, UK

${ }^{c}$ Public and Environmental Health Research Unit, London School of Hygiene and Tropical Medicine, Keppel Street, London, WC1E 7HT, UK

Address for correspondence

Sung $\mathrm{H}$. Hong

The Bartlett School of Graduate Studies (1-19 Torrington Place Site), University

College London, Gower Street, London, WC1E 6BT, United Kingdom

Tel: $+44(0) 2076798234$

Fax: +44 (0)2079161887

E-mail: ucftshh@ucl.ac.uk

Jan Gilbertson

The Centre for Regional Economic and Social Research, Sheffield Hallam University, City Campus, Howard Street, Sheffield, S1 1WB, United Kingdom

Tel: +44 (0)1142253539

Fax: +44 (0)114225 2197

E-mail: J.M.Gilbertson@shu.ac.uk 


\begin{abstract}
This study investigates the effect of England's Warm Front energy efficient refurbishment scheme on winter thermal comfort in low-income dwellings. The analysis is based on an extensive survey of some 2500 dwellings selected from five major urban areas in England over the winters of 2001/02 and 2002/03. The surveys were carried out either before or after the introduction of retrofit insulation and energy efficient heating system. Self-reported thermal comfort (measured on a seven-point scale) and indoor temperature in the living room and in the main bedroom were recorded twice daily at 8 a.m. and 7 p.m. over 11 consecutive days. Results show that Warm Front was effective in increasing the mean indoor temperature from $17.1^{\circ} \mathrm{C}$ to $19.0^{\circ} \mathrm{C}$ leading to an increase in the proportion of households feeling thermally 'comfortable' or warmer from $36.4 \%$ to $78.7 \%$. Warm Front also led to a slight increase in the whole house neutral temperature, i.e. the temperature at which most residents feel thermal neutrality, from $18.9^{\circ} \mathrm{C}$ to $19.1^{\circ} \mathrm{C}$ mainly from reduced clothing level associated with greater energy efficiency. Predicted Mean Vote, which is the standard thermal comfort model in ISO Standard 7730 predicted a higher neutral temperature of $20.4^{\circ} \mathrm{C}$ compared to $18.9^{\circ} \mathrm{C}$ found to be ideal among the average Warm Front households.
\end{abstract}

\title{
Keywords
}

Thermal comfort; PMV; Indoor temperature; Fuel poverty; Energy efficiency; Take-back 


\section{Introduction}

About 2.3 million households in England are currently estimated to be in fuel poverty, and with increasing energy cost, this figure is likely to rise [1]. A household is classified as being fuel poor if a fuel bill in excess of $10 \%$ of income is required to maintain adequate domestic thermal comfort (living room: $21^{\circ} \mathrm{C}$, bedroom: $18^{\circ} \mathrm{C}$ ) in winter. Fuel poverty is caused by a combination of low income, high energy cost and energy inefficient dwelling; households living in fuel poverty generally experience poor quality of life and increased health risk from prolonged exposure to cold temperature [2].

Under the fuel poverty strategy set out by the UK government in 2001, England aims to eliminate fuel poverty by the year 2010 among the vulnerable households, i.e. families with older people or young children or with disabilities or with a long-term illnesses, the groups most susceptible to cold-related ill-health [3]. By recognizing poor energy efficiency in dwellings as one of the main causes of fuel poverty, the national strategy is based on the introduction of energy efficiency grant through a scheme titled Warm Front [4]. The scheme targets low-income households living in the private sector by providing funds for the installation of insulation, energy efficient heating system and draught proofing. Warm Front aims to reduce the burden of fuel cost which in turn is expected to encourage the householders to take up some of the cost savings benefit as improved thermal comfort. Evidence from a previous study has shown that Warm Front resulted in a $1.6^{\circ} \mathrm{C}$ rise in the living room temperature and a $2.8^{\circ} \mathrm{C}$ rise in the bedroom temperature [5]. These improvements are likely to have a positive impact on thermal comfort, well-being and health [6, 7].

In 2001, a national evaluation of the health impact of Warm Front was initiated, a part of which entailed the collection of thermal comfort data from some 2500 dwellings. This study examines the impact of insulation and heating on field-surveyed domestic 
thermal comfort in low-income English dwellings in winter. The efficacy of the thermal comfort standard adopted in ASHRAE 55 [8] and ISO 7730 [9] in predicting domestic thermal comfort in winter is also examined.

\section{The Warm Front energy efficiency scheme}

In year 2000, the Warm Front energy efficiency scheme was launched in England as the main component of government's aim to tackle fuel poverty among the vulnerable households living in private tenure by providing grants for the installation of energy efficiency measures [4]. Eligibility for the grant is based on the receipt of a specific 'passport' benefit - used as proxy indicator of fuel poverty - and having a household member in the vulnerable group classified as those aged below 16 or aged 60 or more or disabled or those suffering from a long-term illness.

By 2005 about 1.1 million households in England have benefited from this scheme. Until 2005, two grant schemes were available: the 'Warm Front' with a maximum grant limit of $£ 1500$ for families with children under the age of 16 and the 'Warm Front Plus' with a maximum grant limit of $£ 2500$ for households with a member aged 60 or over. Both grants offered cavity wall insulation, loft insulation and draught proofing but differed in that a gas central heating was provided for the elderly group and gas wall heaters for the younger households. In 2005, the scheme was upgraded to include a gas central heating system for all of its recipients. This study is based on the scheme prior to the 2005 upgrade.

\section{Thermal comfort standard}

ASHRAE Standard 55 and ISO Standard 7730 are the most widely used thermal comfort standards in contemporary thermal comfort research. Both standards are essentially based on a 'heat-balance' model that takes into account the environmental 
factors of temperature, humidity and air speed and personal factors of clothing and metabolic rate to give a thermal comfort sensation described by a Predicted Mean Vote (PMV). PMV uses a seven-point index, ranging from -3 (cold) to 3 (hot), to measure the thermal comfort sensation most likely to be experienced by a group of people in a given environment under a steady state condition. The PMV model was developed by Fanger based on experiments undertaken in climate chambers [10].

ASHRAE Standard 55 also incorporates an optional standard known as the 'adaptive' model specifically designed to predict thermal comfort in naturally ventilated buildings. This model compensates for the limited effectiveness of the heat balance model in predicting the often wider comfort range observed in naturally ventilated buildings. The adaptive model uses the outdoor temperature as the key variable in predicting the comfort range [11-14].

The application of these standards, however, is limited to the use in 'sedentary or near sedentary physical activity levels typical of office work' [8] since they were predominantly developed (heat balance model) and tested (adaptive model) against field measurements taken from office environment. The applicability of the heat balance model was indeed found to be 'inappropriate' when predicting the thermal comfort condition in air conditioned domestic environment in the US [15] and likewise when applying the adaptive model to naturally ventilated dwellings in California [16]. Little study has so far been undertaken in examining the effectiveness of the PMV model in heated dwellings in winter.

\section{Potential impact of insulation and heating on thermal comfort}

Warm Front aims to increase thermal comfort mainly by increasing the indoor temperature through the installation of insulation and energy efficient heating system. 
Insulation increases the mean indoor temperature by reducing the rate of heatloss through the building fabric while a central heating system increases the mean indoor temperature by improving the distribution of heat throughout the building and allowing higher demand temperature. The cost savings from improved enegy performance can in turn encourage the householders to take up some of the benefit by increasing the demand temperature, a process known as the 'take-back factor' or the 'rebound effect'.

Insulation and central heating also reduce the elements that can contribute to local thermal discomfort. Warmer external walls from insulation reduce discomfort arising from radiant temperature asymmetry and from localised downdraft caused when warm air touches cold surfaces [17]. By improving the uniformity of temperature distribution in a dwelling, gas central heating can also reduce the impact of 'thermal stress' associated with sudden changes in temperature when moving from room to room [18, 19].

\section{Methods}

\subsection{Warm Front survey}

In 2001, the 'Health Impact Evaluation of Warm Front' study was commissioned to investigate the effect of Warm Front on resident health in England. The Warm Front study was designed to combine an empirical survey with statistical and epidemiological analysis to model the potential impact of improved energy efficiency on householders, mental and physical health and quality of life. The heart of the investigation involved documenting and quantifying changes in hypothesized elements such as energy efficiency [20], ventilation [21], indoor environmental conditions [22] and thermal comfort in a representative sample.

The study involved the collection of extensive household and property condition data 
from some 3500 dwellings selected from five major urban clusters around Birmingham, Liverpool, Manchester, Newcastle and Southampton to provide a good representation of the different household characteristic, housing types and climate conditions in England. The data was collected over two successive winters of 2001/02 and 2002/03 by a combination of surveying, interviewing and monitoring by trained surveyors. A sub-sample of 2519 dwellings was targeted for the thermal comfort study.

The basic survey design is based on cross-sectional comparisons between the preand post-improvement households measured in the same winter. Although statistically less efficient, this method is less open to bias than comparing the same dwellings before and after Warm Front in consecutive winters.

\subsection{Comfort Vote}

A self-reported thermal comfort diary was supplied to a designated occupant in each household, usually the head of household or spouse, who were instructed to record thermal comfort perception and the room temperature twice daily at 8 a.m. and 7 p.m. in the living room and in the main bedroom during 11 consecutive days. The selection of the hours is based on the assumption that dwellings are most likely to be occupied and heated at these times. The following information was also recorded in the comfort diaries: date of the diary delivery and collection, respondent gender, Warm Front intervention status, diary entry hour if it differed more than half an hour from the designated hours, living room temperature, bedroom temperature, occupant clothing and occupant activity level.

comfort - In response to the diary question 'In the middle of the room, the room felt' the respondents were asked to record their subjective thermal comfort based on a descriptive seven-point Comfort Vote (CV) index: 'much too cool' (-3), 'too cool' (-2), 
'comfortably cool' (-1), 'comfortable' (0), 'comfortably warm' (1), 'too warm' (2) and 'much too warm' (3). Corresponding to each index, a numerical values was assigned (shwon in parenthesis) in accordance to the convention of ISO Standard 7730.

\subsection{Predicted Mean Vote}

The PMV index was calculated with the aid of Excel spreadsheet using the equation derived by Fanger $[10,23]$. The input variables of indoor air temperature, radiant temperature, relative humidity, air speed, clothing level and activity level required to determine PMV were derived as follows:

Indoor air temperature - Householders were requested to record the indoor air temperature using Boddingtons liquid crystal temperature strips supplied with the comfort diaries. The temperature strips were each placed in the living room and the main bedroom and temperature measurements taken simultaneously when comfort assessment was made. In $48 \%$ of the case study dwellings, Gemini TinyTag dataloggers were also used to record the indoor temperature at half-hourly intervals in the two rooms. The loggers and the temperature strips were placed away from direct sources of heat and light on a sideboard or shelf at around waist height, approximately $1 \mathrm{~m}$ from the ground.

A comparison between the two types of temperature measurement showed that the strip monitored temperature was on average $0.3^{\circ} \mathrm{C}$ lower than the logger monitored temperature but with a large standard deviation of $2.2^{\circ} \mathrm{C}$. In addition to the possibility of erroneous reading, the strip-temperature performance would have been compromised if the strips had come in contact with objects such as furniture or the diary book (if temperature strips were used as bookmarks) just prior to temperature reading. On the other hand, the logger-temperature also presented a potential source 
of error since it relied on the accuracy of the diary recorded hours to link the temperature data with the thermal comfort experience. Despite the instruction to fill in the diary at the two specified hours, it is doubtful that this was faithfully carried out by the householders. In this study, it was decided to use the strip- temperature for the internal temperature analysis to maintain the temporal connection to the field-surveyed thermal comfort experience.

Mean radiant temperature - A computer based environment simulation tool called EnergyPlus was used to predict the theoretical mean radiant temperature in the centre of a hypothetical $5 \mathrm{~m} \times 4 \mathrm{~m} \times 2 \mathrm{~m}$ room representing the living room and the main bedroom in a typical Warm Front dwelling. The hypothetical living room was assumed to be located on the ground floor and the main bedroom on the first floor. The number of exposed walls was varied to reflect the type of dwelling i.e. terraced, semi-detached or detached, and separate predictions were made for the insulated and the noninsulated conditions. All exposed floors were assumed to be un-insulated and the exposed ceilings having $100 \mathrm{~mm}$ loft insulation. A standard heating regime was assumed in all cases (7 - 9 a.m. and 4 - 11 p.m.) for the period of December 1 to March 31 based on Birmingham weather.

The 'actual' radiant temperature was estimated by adjusting the strip monitored indoor air temperature by the difference observed between the modelled air temperature and the modelled mean radiant temperature. The simulation result showed that in the morning the air temperature was on average $0.5^{\circ} \mathrm{C}$ lower and in the evening about $1.0^{\circ}$ $\mathrm{C}$ higher than the mean radiant temperature. Insulation, on the other hand, reduced the difference only by about $0.1^{\circ} \mathrm{C}$ perhaps due to the window conditions remaining the same. 
Indoor relative humidity - The indoor relative humidity was continuously monitored in the living room and the main bedroom at half-hour intervals using Gemini TinyTag dataloggers in half of the case study dwellings. For the other half of the sample, the relative humidity was estimated by substituting the actual monitored value based on regional proximity, occupancy number and the type of heating system. The potential error introduced from this method of estimation is considered to be small since the relative humidity level typically experienced in the UK dwellings in winter is considered to have a negligible impact on thermal comfort $[24,25]$.

Air speed - No air movement was measured as a part of the Warm Front survey. Instead, a minimum air velocity of $0.1 \mathrm{~m} / \mathrm{sec}$ was assumed for all cases by assuming little window operation on account of the cold external temperature.

Clothing - In response to the question 'Please tick the box which best describes your clothing', the respondents were asked to select the appropriate clothing description from a check-list shown in Table 1. The table shows the estimated insulation value rated in units of clo $\left(1 \mathrm{clo}=0.155 \mathrm{~m}^{2} \mathrm{KW}^{-1}\right)$ corresponding to each clothing level [25]. For sedentary householders ('very little activity') 0.15 clo was further added to the total insulation level in order to take into account the insulation effect of a chair [26].

Table 1

Clothing description and the equivalent (estimated) insulation level.

\begin{tabular}{lc}
\hline \multicolumn{1}{c}{ Clothing description } & Insulation level (clo) ${ }^{\mathrm{a}}$ \\
\hline Lightweight trousers or skirt/dress, with short sleeved shirt or blouse & 0.50 \\
\hline $\begin{array}{l}\text { Long sleeved pullover or cardigan with medium weight trousers, } \\
\text { skirt or dress }\end{array}$ & 0.75 \\
\hdashline $\begin{array}{l}\text { Heavyweight pullovers or jackets, thick trousers or dresses or } \\
\text { thermals with medium weight clothing }\end{array}$ & 1.10 \\
$\begin{array}{l}\text { Outdoor clothes or heavy clothing with thermals or extra layers of } \\
\text { thick clothing }\end{array}$ & 1.55 \\
\hline${ }^{a}$ Insulation effect of chair excluded $(0.15$ clo).
\end{tabular}


Activity - In response to the question 'In the last half hour how active have you been' the respondents were asked to select the appropriate activity level from a check-list shown in Table 2. The table shows the estimated metabolic rate in units of met corresponding to each activity level [25].

Table 2

Activity level and the equivalent (estimated) metabolic rate.

\begin{tabular}{llc}
\hline & Activity level & Metabolic rate (met) \\
\hline Very little activity & $\begin{array}{l}\text { Sitting, lying down, standing, little } \\
\text { movement around home }\end{array}$ & 1.0 \\
Light activity & $\begin{array}{l}\text { Moving around home, cooking, light } \\
\text { housework, light DIY }\end{array}$ & 1.5 \\
More vigorous activity & $\begin{array}{l}\text { Brisk walking, scrubbing, vacuuming, } \\
\text { coming in from outside. }\end{array}$ & 2.0 \\
\hline
\end{tabular}

\subsection{Neutral temperature}

The neutral temperature indicates the ambient temperature at which the occupants are mostly likely to experience thermal comfort, i.e. index of 0 on the seven-point thermal comfort scale. For each dwelling, the neutral temperature was predicted using a linear model regressed against the indoor temperature as a function of the CV using the "FORECAST" function in Excel. The neutral temperature was predicted only for those dwellings which recorded three or more different thermal comfort sensations in order to guarantee a good fit of the regression lines. The neutral temperature was obtained from a total of 1951 dwellings.

\subsection{External temperature}

The external temperature was measured using Gemini TinyTag dataloggers placed in central locations in each of the surveyed urban clusters. The measurements were continuously recorded at half-hourly intervals over the two surveyed winters of 2001/02 and 2002/03 spanning the months from November to April. In this study, the monitored external temperature was used as an indicator of whether the temperatures were low 
enough to require space heating over the surveyed period.

\section{Characteristic of the case study dwellings and households}

$52 \%$ of the case study dwellings were of terraced type followed by $37 \%$ semi-detached. In comparison, the terraced dwellings in England make up only $30 \%$ and semidetached $31 \%$. In contrast, flats and detached dwellings comprised only $11 \%$ of the Warm Front sample compared to the English average of $38 \%$.

The Warm Front properties were of the older stock with $85 \%$ pre-dating 1965 compared to $60 \%$ in England [27]. This age difference is also reflected in the type of wall construction with $32 \%$ of the Warm Front dwellings having solid wall construction (typical: $225 \mathrm{~mm}$ brick masonry, no cavity space) compared to $24 \%$ in England. The rest were predominantly of masonry cavity wall construction (typical: 105mm external brick masonry $-50 \mathrm{~mm}$ air space $-105 \mathrm{~mm}$ internal brick or concrete masonry) while timber or steel or other construction type made up only $3 \%$ as in England.

The mean SAP rating (a measure of domestic space and water heating energy efficiency ranging from a score of 0 to 120 where higher values represent greater energy efficiency) of the pre-Warm Front dwellings was 41 compared to 51 in England in 2001 . $82 \%$ of the pre-Warm Front dwellings had either no or partial insulation and $75 \%$ had no gas central heating. The mean SAP rating increased to 62 post-Warm Front.

The mean floor area per person was $52 \mathrm{~m}^{2}$ which is $18 \%$ greater than the English average of $44 \mathrm{~m}^{2}$. This was due to single occupancy households comprising $62 \%$ of the elderly households and $51 \%$ of the younger households, both of which were higher than the English average of $41 \%$. $58 \%$ of the case study dwellings were represented 
by households that included an elderly person; $67 \%$ were suffering from a longstanding illness, disability or infirmity. Owner-occupied dwellings constituted $80 \%$ of the Warm Front dwellings and privately rented dwellings $20 \%$.

\section{Results}

\subsection{External temperature}

The mean monitored external temperature (November - April) was $6.9^{\circ} \mathrm{C}$ in both winters (winter 1 : SD $3.9^{\circ} \mathrm{C}$; winter $2: \mathrm{SD} 4.1^{\circ} \mathrm{C}$ ). The temperature was the coolest in Newcastle at $6.0^{\circ} \mathrm{C}\left(\mathrm{SD} 3.8^{\circ} \mathrm{C}\right)$ and the highest in Southamption at $8.2^{\circ} \mathrm{C}\left(\mathrm{SD} 3.8^{\circ} \mathrm{C}\right)$. The coolest mean monthly temperature was recorded in December 2001 at $3.2^{\circ} \mathrm{C}$ (SD $\left.3.3^{\circ} \mathrm{C}\right)$ and the highest in April, 2002 at $10.1^{\circ} \mathrm{C}\left(\mathrm{SD} 4.4^{\circ} \mathrm{C}\right)$. The monitored external conditions indicate that the temperatures were low enough to require indoor heating when the thermal comfort surveys were being carried out.

\subsection{Response rate}

A total of 2399 'completed' thermal comfort diaries were obtained from 2519 dwellings that were provided with the thermal comfort diaries. $68 \%$ of the diary respondents were female and 263 dwellings (11\%) provided completed diaries for the full 11 days. Diaries were completed for an average number of 8.5 days with $75 \%$ of the households supplying data for 8 days or more.

\subsection{Impact of Warm Front on thermal comfort}

The variability of CV between the pre and the post-Warm Front dwellings is compared in Fig. 1a and b respectively disaggregated by the room type (living room, bedroom), time of day (8 a.m., 7 p.m.) and the age of the vulnerable household member $(<60 \mathrm{yrs}$, $>=60 \mathrm{yrs}$ ). The mean indoor temperatures - as recorded by the temperature strips associated with the mean $\mathrm{CV}$ indices are included in parenthesis. The shaded band 
indicates the thermally 'comfortable' range $(-0.5 \leq \mathrm{CV} \leq 0.5)$.

Fig. 1a shows that the mean CV of all the groups, except for the living room and the evening, is in the 'comfortably cool' $(-1.5 \leq \mathrm{CV} \leq-0.5)$ range. The coolest condition was found in the bedroom and in the morning with an average CV of -1.1 and mean temperatures of $16.0^{\circ} \mathrm{C}\left(\mathrm{SD} 2.8^{\circ} \mathrm{C}\right)$ and $16.3^{\circ} \mathrm{C}\left(\mathrm{SD} 2.5^{\circ} \mathrm{C}\right)$ respectively. These temperatures are clearly at levels which are known to increase the risk of respiratory infection from cold strain [28]. The living room and the evening were the only two groups with mean comfort levels in the 'comfortable' $(-0.5 \leq \mathrm{CV} \leq 0.5)$ range with mean temperatures of $18.3^{\circ} \mathrm{C}\left(\mathrm{SD} 2.3^{\circ} \mathrm{C}\right)$ and $17.9^{\circ} \mathrm{C}\left(\mathrm{SD} 2.4^{\circ} \mathrm{C}\right)$ respectively. $23.7 \%$ of the households in the pre-Warm Front group found the indoor condition 'too cool' $(20.1 \%)$ or 'much too cool' (3.5\%), 40\% found it 'comfortably cool', $33.3 \%$ 'comfortable' and only $3.1 \%$ 'comfortably warm'.

The benefit of Warm Front is evident in Fig. $1 \mathrm{~b}$ with improved thermal comfort condition across all the groups and their mean values all within the 'comfortable' range. The greatest improvement was observed in the elderly group, mainly from the introduction of gas central heating, increasing the mean $\mathrm{CV}$ index by about 1 unit and the temperature by $2.3^{\circ} \mathrm{C}$ to $19.1^{\circ} \mathrm{C}\left(\mathrm{SD} 2.1^{\circ} \mathrm{C}\right)$ surpassing the condition in the younger households. A large improvement was also observed in the bedroom with a $2.2^{\circ} \mathrm{C}$ rise followed by the morning with a $2.0^{\circ} \mathrm{C}$ rise, the two groups that were the coolest before the upgrade.

Warm Front had the least impact in the younger households which saw an increase in the mean $\mathrm{CV}$ by 0.5 units and the temperature by $1.1^{\circ} \mathrm{C}$. The impact in the living room and in the evening was also small due to these groups already having maintained high 
temperature and comfort condition prior to the upgrade.

Following the Warm Front intervention, the proportion of households that were 'comfortable' or warmer increased from $36.4 \%$ to $78.7 \%$. The proportion of dwellings with mean temperatures below $16^{\circ} \mathrm{C}$ also reduced from $30.2 \%$ to $7.2 \%$. Despite the upgrade, $6.6 \%$ of the householders still found the living room 'too cool' or 'much too cool'. These conditions were also found in $14.5 \%$ in the bedroom, $15.1 \%$ in the morning, $5.3 \%$ in the evening, $7.9 \%$ in the younger group and $1.7 \%$ in the elderly group.

Fig. 1.

Impact of Warm Front on thermal comfort (Comfort Vote) disaggregated by room type, time of day and age of vulnerable householder. (Solid horizontal line indicates mean Comfort Vote; monitored indoor temperature is included in parenthesis; the box represents interquartile (IRQ) range (1st quartile to 3rd quartile); the vertical lines extend to the highest and the lowest values not considered as outliers (<3rd quartile $+1.5 \times I R Q,>1$ st quartile $-1.5 \times I R Q$ ); black dots represent moderate outliers ( $>3 \mathrm{rd}$ quartile $+1.5 \times \mathrm{IRQ},<1$ st quartile $-1.5 \times \mathrm{IRQ}$ ); white dots represent extreme outliers ( $>3$ rd quartile $+3 \times I R Q,<1$ st quartile $-3 \times I R Q$ ); The shaded area indicates the 'comfortable' range).

(a) Pre-Warm Front $(\mathrm{n}=1131)$

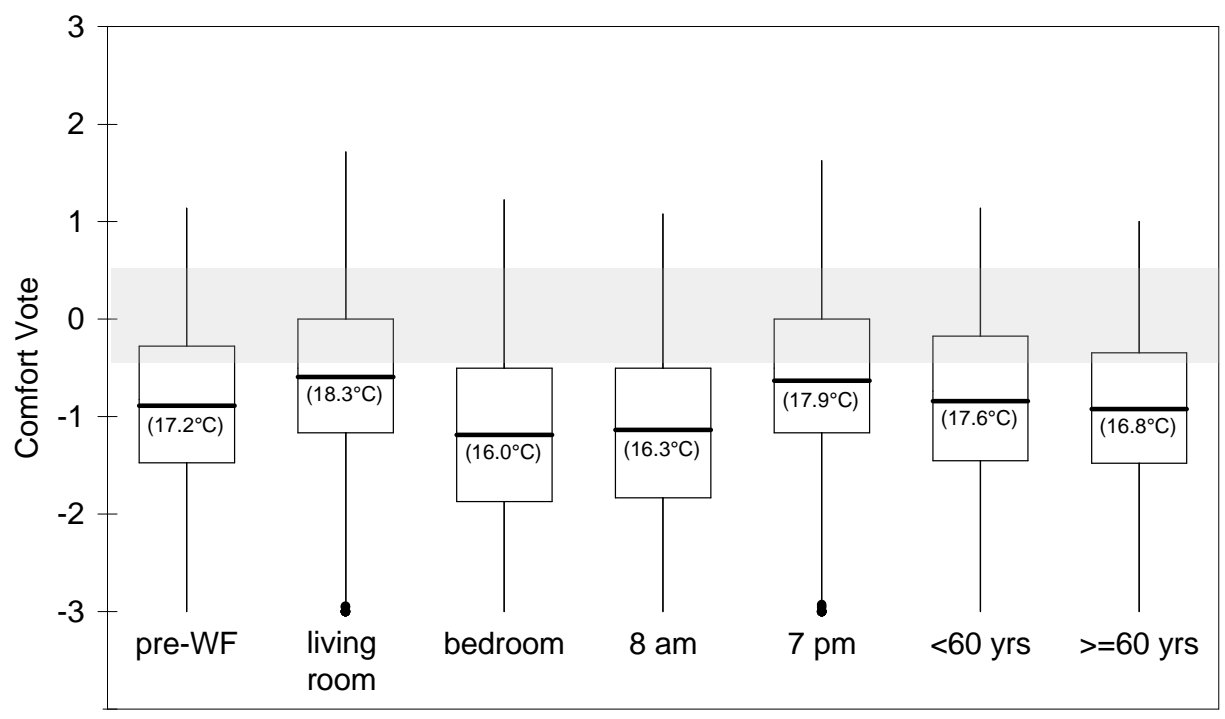

(b) Post-Warm Front $(\mathrm{n}=1130)$ 


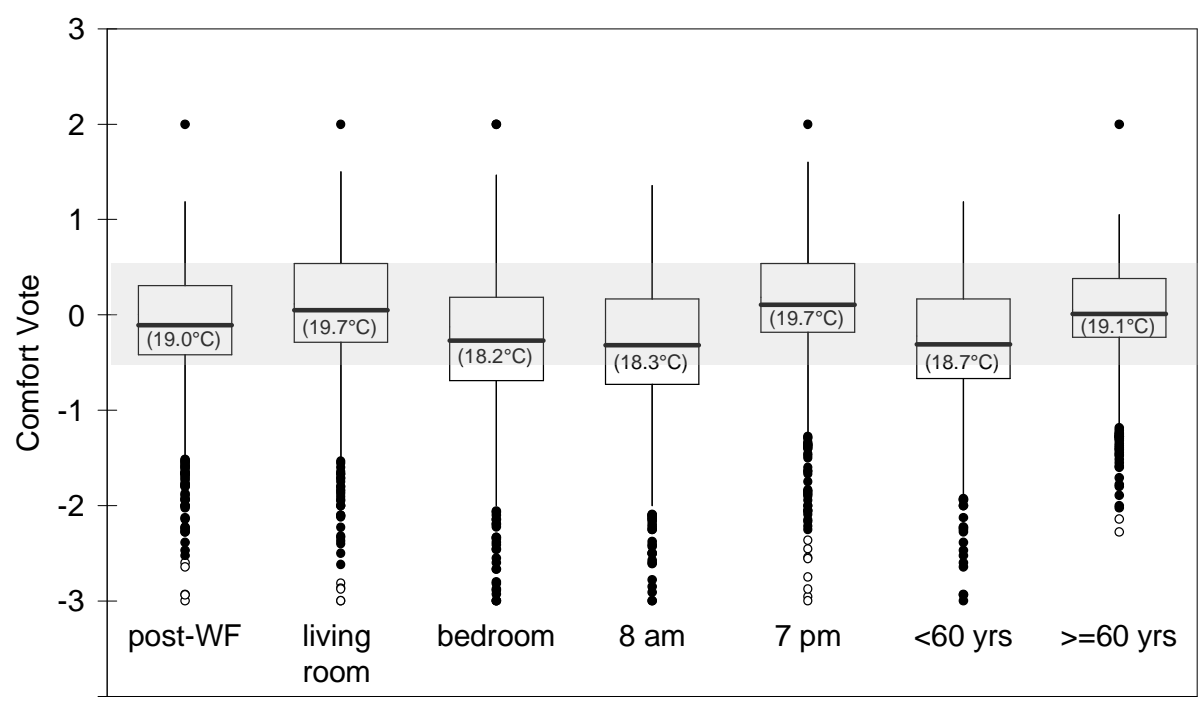

\subsection{Comfort Vote and Predicted Mean Vote compared}

The boxplots in Fig. $2 a$ and $b$ compare the variability of the self-reported CV and the theoretical PMV in relation to the monitored indoor temperature. Both indices clearly indicate improved thermal comfort with increasing temperature, although the comfort perception can vary considerably within each temperature band. For instance, there were householders who found conditions below $16^{\circ} \mathrm{C}$ to be comfortable while in a few cases temperatures above $21^{\circ} \mathrm{C}$ were considered to be still cool.

A comparison of Fig. $2 a$ and b shows that for the same temperature band, the comfort conditions predicted by PMV are lower than CV by an average of 0.5 unit. This variation seems to result in a difference of $1.5^{\circ} \mathrm{C}$ between the $\mathrm{PMV}$ and the $\mathrm{CV}$ predicted neutral temperatures with the average Warm Front households finding $18.9^{\circ} \mathrm{C}$ to be comfortable while the PMV model predicted a higher level of $20.4^{\circ} \mathrm{C}$ as shown in Fig. 3. The minimum air speed of $0.1 \mathrm{~m} / \mathrm{sec}$ specified for the PMV model can't explain the discrepancy between CV and PMV since a greater air speed would have resulted in lower PMV scores. 
Fig. 2.

Comfort Vote and Predicted Mean Vote in relation to indoor temperature. (The box represents interquartile (IRQ) range (1st quartile to 3rd quartile) with the mean shown in solid horizontal line; the vertical lines extend to the highest and the lowest values not considered as outliers ( $<3$ rd quartile $+1.5 \times \mathrm{IRQ},>1$ st quartile $-1.5 \times \mathrm{IRQ}$ ); black dots represent moderate outliers (>3rd quartile $+1.5 \times \mathrm{IRQ},<1$ st quartile $-1.5 \times \mathrm{IRQ}$ ); white dots represent extreme outliers ( $>3$ rd quartile $+3 \times I R Q,<1$ st quartile $-3 \times I R Q$ ); The shaded area indicates the 'comfortable' range).

(a) Comfort Vote $(\mathrm{n}=2399)$

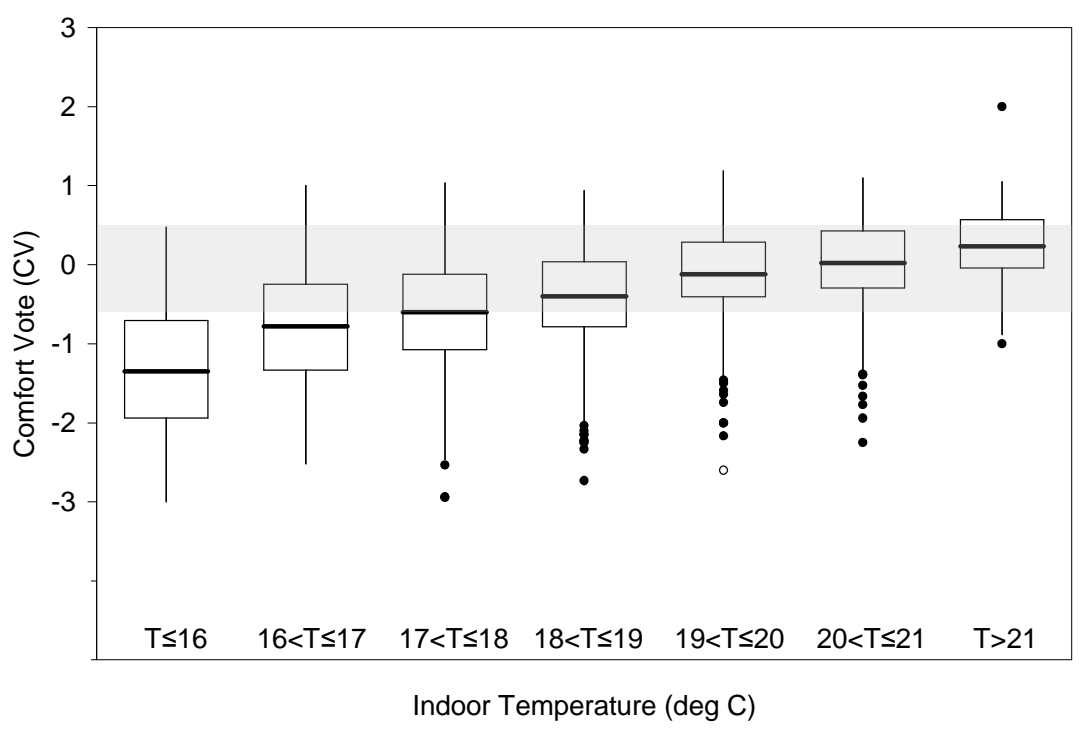

(b) Predicted Mean Vote $(n=2360)$

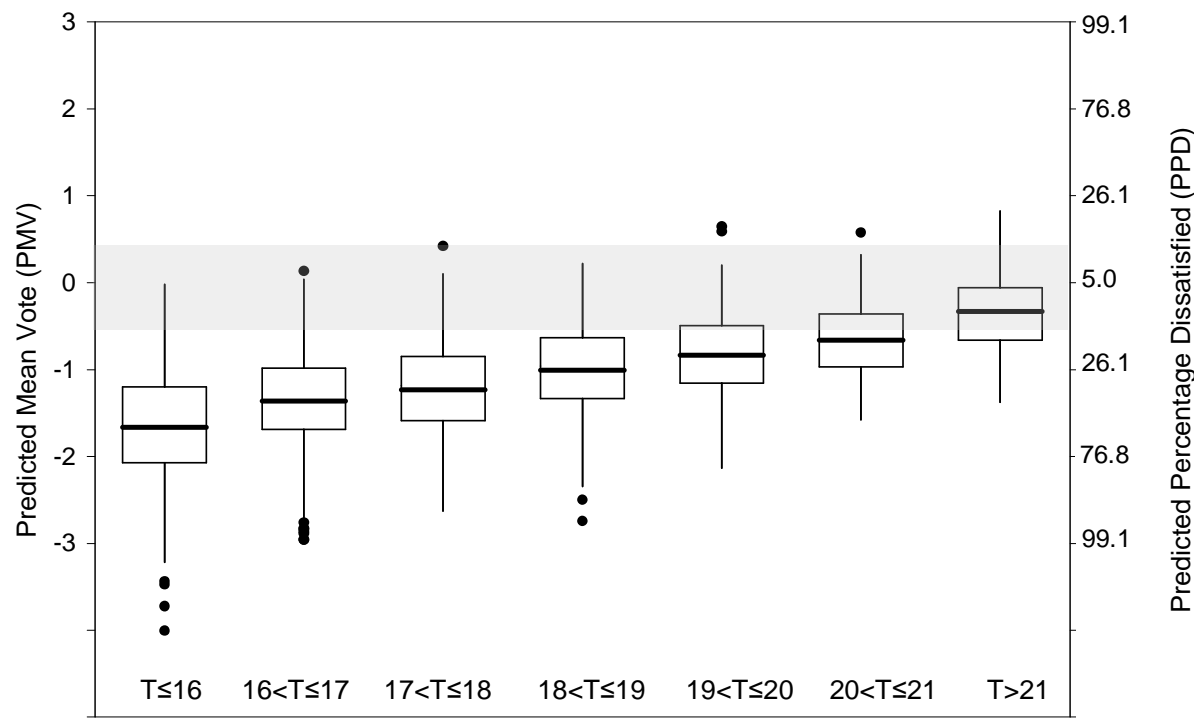

Indoor Temperature $(\operatorname{deg} \mathrm{C})$ 
Fig. 3.

Neutral temperature predicted by Comfort Vote and Predicted Mean Vote. Neutral temperature is estimated from the regression line when thermal comfort is neutral (CV, $P M V=0)$.

(a) Comfort Vote

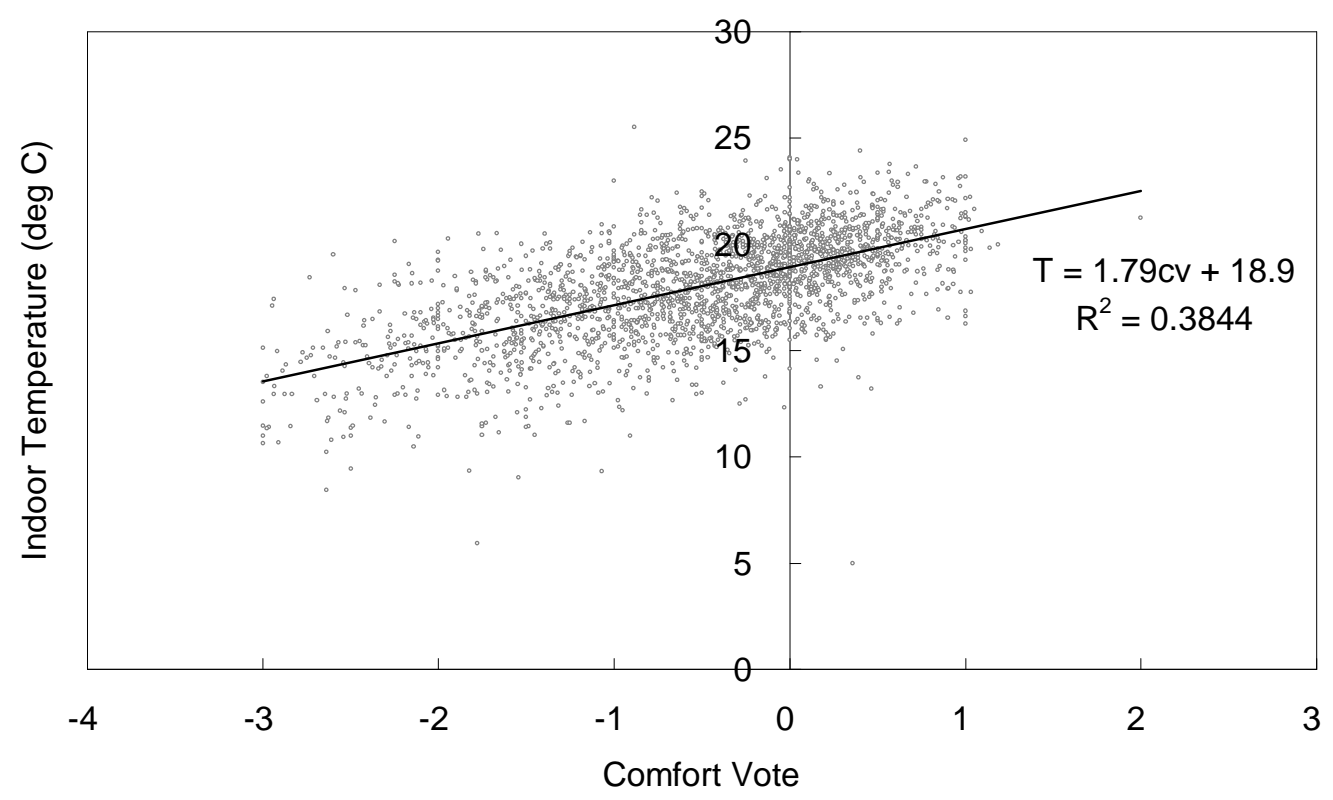

(b) Predicted Mean Vote

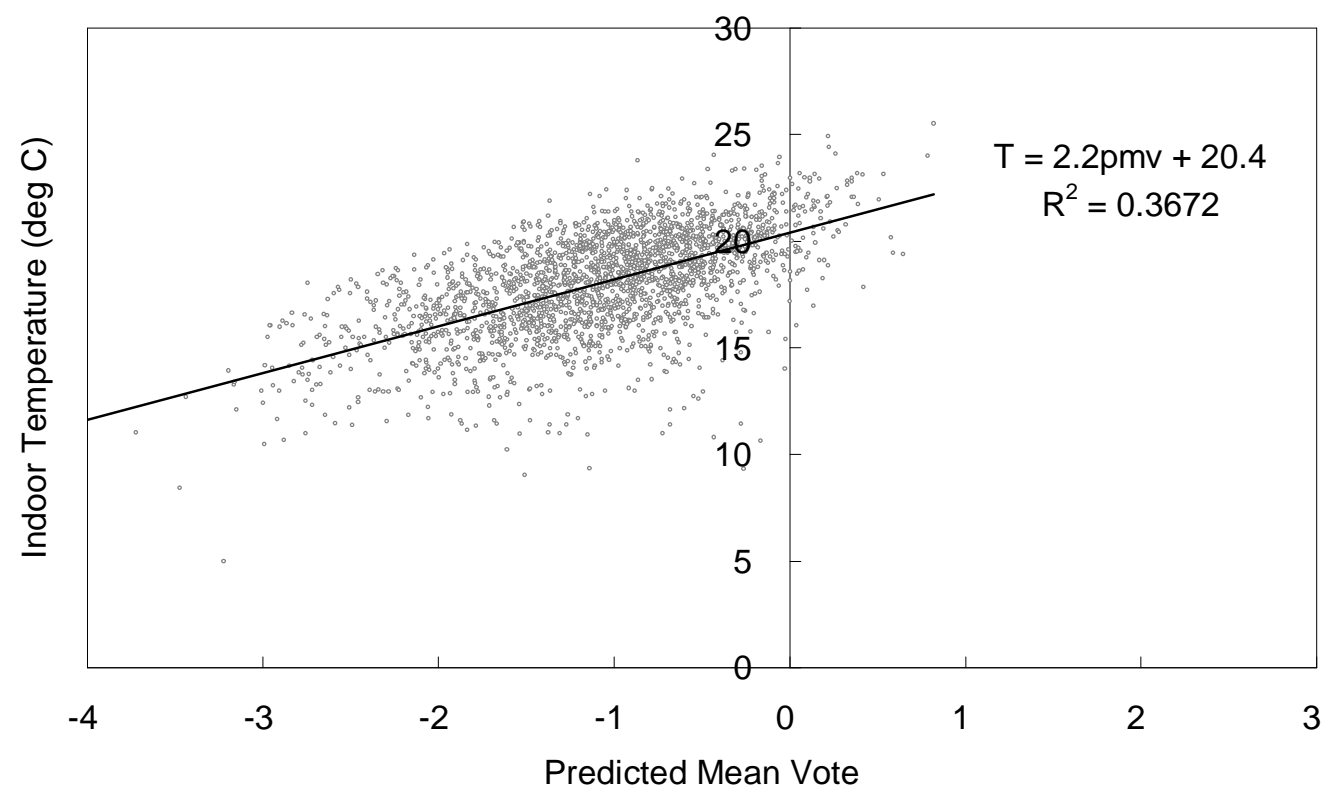


7.5. Impact of insulation and central heating on thermal comfort and clothing

The impact of full insulation (loft and cavity wall insulation) and central heating on CV and the clothing level is compared in Table 3. The table shows the mean values and the change relative to the baseline group (no insulation and no central heating). The partially insulated dwellings (loft insulation only or cavity wall insulation only) are excluded from this comparison.

The combination of insulation and central heating resulted in the greatest rise in CV by an average index of $1.01(95 \% \mathrm{Cl}: 0.90,1.11)$ followed by central heating alone by 0.60 (95\% Cl: $0.47,0.72)$ followed by insulation alone by $0.42(95 \% \mathrm{Cl}: 0.30,0.55)$. The combination of insulation and gas central heating measures resulted in a mean CV index close to neutral $(\mathrm{CV}=-0.05,95 \% \mathrm{Cl}:-0.11,0.02)$.

Although small, the level of clothing was found to decrease with increased energy efficiency. Compared to the baseline group, the mean clothing insulation level was 0.07 clo (almost equivalent to the insulation level provided by a T-shirt) less in dwellings that were fully insulated and centrally heated. Central heating by itself was associated with a reduction in the clothing level by 0.04 clo and full insulation by 0.03 clo. Insulation and central heating, on the other hand, were found to have no significant impact on the self-reported activity level (not shown). 
Table 3

Impact of insulation and central heating on thermal comfort (Comfort Vote) and clothing.

\begin{tabular}{|c|c|c|c|c|c|c|}
\hline \multirow[b]{2}{*}{ Intervention type } & \multicolumn{3}{|c|}{ Comfort Vote } & \multicolumn{3}{|c|}{ Clothing (clo) } \\
\hline & No & Mean & $\begin{array}{c}\text { Difference relative } \\
\text { to baseline group } \\
(95 \% \mathrm{Cl})\end{array}$ & No & Mean & $\begin{array}{c}\text { Difference relative } \\
\text { to baseline group } \\
(95 \% \mathrm{Cl})\end{array}$ \\
\hline No intervention ${ }^{a}$ & 297 & -1.05 & 0 & 292 & 0.82 & 0 \\
\hline Insulation only ${ }^{b}$ & 217 & -0.63 & $0.42(0.30,0.55)^{\mathrm{e}}$ & 217 & 0.78 & $-0.03(-0.06,0.00)^{\mathrm{e}}$ \\
\hline Heating only ${ }^{c}$ & 226 & -0.46 & $0.60(0.47,0.72)^{\mathrm{e}}$ & 224 & 0.78 & $-0.04(-0.07,-0.02)^{e}$ \\
\hline Insulation + heating ${ }^{d}$ & 509 & -0.05 & $1.01(0.90,1.11)^{\mathrm{e}}$ & 503 & 0.75 & $-0.07(-0.09,-0.05)^{\mathrm{e}}$ \\
\hline
\end{tabular}

a No insulation, no gas central heating.

b Cavity wall insulation, loft insulation $(>=100 \mathrm{~mm})$, no gas central heating.

${ }^{c}$ No insulation, gas central heating with or without local heater(s).

d Cavity wall insulation, loft insulation ( $>=100 \mathrm{~mm}$ ), gas central heating with or without local heater(s).

e Mean difference to the baseline group is significant to 0.05 level.

7.6. Impact of insulation and central heating on indoor and neutral temperatures

Table 4 shows the impact of full insulation and gas central heating on the mean indoor temperature and the neutral temperature. The table shows the mean values and the change relative to the baseline group. Again, the partially insulated dwellings are excluded from this comparison.

The combination of insulation and central heating resulted in the greatest increase in the indoor temperature by $2.83^{\circ} \mathrm{C}(95 \% \mathrm{Cl}: 2.52,3.14)$ followed by central heating alone by $1.89^{\circ} \mathrm{C}(95 \% \mathrm{Cl}: 1.51,2.26)$ and insulation by $1.19^{\circ} \mathrm{C}(95 \% \mathrm{Cl}: 0.81,1.57)$. The neutral temperature, which in theory should remain constant, was in practice found to increase with energy efficiency measures, in particular the change was statistically significant in relation to central heating. Full insulation and central heating were associated with the greatest increase in the neutral temperature by $0.63^{\circ} \mathrm{C}(95 \% \mathrm{Cl}$ : $0.31,0.95)$ followed by gas central heating alone by $0.36^{\circ} \mathrm{C}(95 \% \mathrm{Cl}:-0.02,0.74)$ whereas full insulation by itself was found to have no impact. 
The similarity between the indoor temperature $\left(19.24^{\circ} \mathrm{C}, \mathrm{SD} 1.86^{\circ} \mathrm{C}\right)$ and the neutral temperature $\left(19.32^{\circ} \mathrm{C}, \mathrm{SD} 1.69^{\circ} \mathrm{C}\right)$ in the insulated and centrally heated group indicates that thermal comfort was achieved in this group (CV: -0.05 , SD 0.62). In contrast, despite the lowest neutral temperature $\left(18.69^{\circ} \mathrm{C}, \mathrm{SD} 2.47^{\circ} \mathrm{C}\right)$ observed in the baseline group, the lower monitored indoor temperature $\left(16.42^{\circ} \mathrm{C}, \mathrm{SD} 2.41^{\circ} \mathrm{C}\right)$ indicates that thermal comfort cannot be attained in these dwellings without the aid of insulation or gas central heating or both (CV: -1.05 , SD 0.85).

\section{Table 4}

Impact of insulation and central heating on indoor temperature and neutral temperature.

\begin{tabular}{|c|c|c|c|c|c|c|}
\hline \multirow[b]{2}{*}{ Intervention type } & \multicolumn{3}{|c|}{ Indoor temperature $\left({ }^{\circ} \mathrm{C}\right){ }^{\mathrm{e}}$} & \multicolumn{3}{|c|}{ Neutral temperature $\left({ }^{\circ} \mathrm{C}\right)$} \\
\hline & No & Mean & $\begin{array}{c}\text { Difference relative to } \\
\text { baseline group } \\
(95 \% \mathrm{Cl})\end{array}$ & No & Mean & $\begin{array}{c}\text { Difference relative } \\
\text { to baseline group } \\
(95 \% \mathrm{Cl})\end{array}$ \\
\hline No intervention ${ }^{a}$ & 308 & 16.42 & 0 & 252 & 18.69 & 0 \\
\hline Insulation only ${ }^{\mathrm{b}}$ & 217 & 17.61 & $1.19(0.81,1.57)^{f}$ & 187 & 18.75 & $0.06(-0.32,0.43)$ \\
\hline Heating only ${ }^{c}$ & 228 & 18.30 & $1.89(1.51,2.26)^{f}$ & 179 & 19.06 & $0.36(-0.02,0.74)^{g}$ \\
\hline Insulation + heating ${ }^{d}$ & 512 & 19.24 & $2.83(2.52,3.14)^{f}$ & 384 & 19.32 & $0.63(0.31,0.95)^{f}$ \\
\hline
\end{tabular}

a No insulation, no gas central heating.

b Cavity wall insulation, loft insulation $(>=100 \mathrm{~mm})$, no gas central heating.

${ }^{c}$ No insulation, gas central heating with or without local heater(s).

d Cavity wall insulation, loft insulation ( $>=100 \mathrm{~mm}$ ), gas central heating with or without local heater(s).

e Indoor temperature is the mean of living room and bedroom at 8 a.m. and 7 p.m.

$f$ Mean difference to the baseline group is significant to 0.05 level.

$\mathrm{g}$ Mean difference to the baseline group is significant to 0.06 level.

\subsection{Determinants of thermal comfort}

In addition to the different energy efficiency measures examined above, a number of household and property related variables were examined as potential determinants of thermal comfort using the multivariate analysis. Among those examined, 'satisfaction with the heating system' was associated with a greater level of thermal comfort while the 'presence of moisture and mould' was a strong indicator of thermal discomfort. Although clothing was a significant determinant, increased clothing level was 
associated with greater thermal discomfort indicating that clothing did not offset the thermal discomfort at lower temperatures.

Activity level was not found to be a significant indicator most likely because of the small range of variation observed in the Warm Front sample (1.35 met, SD 0.18). Property characteristics such as building age and type were not significant and likewise household characteristics such as tenure, tenure length, household size, income and ethnic background were also unrelated to thermal comfort. No difference in thermal comfort was found between the two Warm Front age groups once the impact of gas central heating was taken into account. No significant relationship was found between the external temperature and the thermal comfort and likewise in relation to the neutral temperature.

\section{Discussion and conclusion}

\subsection{Thermal comfort}

Warm Front was effective in increasing the mean indoor temperature by $1.9^{\circ} \mathrm{C}$ from $17.1^{\circ} \mathrm{C}\left(\mathrm{SD} 2.3^{\circ} \mathrm{C}\right)$ to $19.0^{\circ} \mathrm{C}\left(\mathrm{SD} 2.1^{\circ} \mathrm{C}\right)$. This resulted in an increase in the mean thermal comfort (CV) from 'comfortably cool' $(-0.9)$ to 'comfortable' $(-0.1)$ with $78.7 \%$ of the post-Warm Front respondents finding the indoor environment to be 'comfortable' or warmer ( $\mathrm{CV} \geq-0.5$ ) compared to only $36.4 \%$ in pre-Warm Front. Increased thermal comfort is a great benefit of the Warm Front scheme in addition to the environmental and health benefits $[6,7,28]$. On the other hand, Warm Front was not entirely successful in removing all of the post-Warm Front occupants from cold living condition with $4.2 \%$ still reporting 'too cool' or colder. In terms of temperature, $28.2 \%$ of the post-Warm Front dwellings still recorded temperatures below $18^{\circ} \mathrm{C}$ and $7.4 \%$ below $16^{\circ} \mathrm{C}$ [29]. 
Insulation and gas central heating measures were both found to have different degrees of impact on the thermal comfort and the indoor temperature. Compared to the baseline case, i.e. dwellings that are non-insulated and non-centrally heated, full insulation alone was associated with a mean increase in CV by 0.42 units $(95 \% \mathrm{Cl}$ : $0.30,0.55)$ and the indoor temperature by $1.19^{\circ} \mathrm{C}\left(95 \% \mathrm{Cl}: 0.81^{\circ} \mathrm{C}, 1.57^{\circ} \mathrm{C}\right)$. Greater impact was observed with gas central heating resulting in an increase in CV by 0.60 units $(95 \% \mathrm{Cl}: 0.47,0.72)$ and the temperature by $1.89^{\circ} \mathrm{C}\left(95 \% \mathrm{Cl}: 1.51^{\circ} \mathrm{C}, 2.26^{\circ} \mathrm{C}\right)$. As expected, the combination of insulation and central heating resulted in the greatest improvement in CV by 1.01 units $(95 \% \mathrm{Cl}: 0.90,1.11)$ and the temperature by $2.83^{\circ} \mathrm{C}$ $\left(95 \% \mathrm{Cl}: 2.52^{\circ} \mathrm{C}, 3.14^{\circ} \mathrm{C}\right)$ bringing the mean thermal comfort level close to neutral (CV $=-0.05,95 \% \mathrm{Cl}:-0.11,0.02)$. The improvements in temperature and thermal comfort clearly demonstrate the process of take-back associated with energy efficiency. While a large portion of the take-back from insulation can be explained as the result of improved thermal performance of the building fabric [30], the take-back associated with central heating supports occupancy behaviour as the primary cause.

\subsection{Neutral temperature}

The take-back from occupancy behaviour seems to be caused not only by the desire to achieve thermal comfort but also due to a change in the thermal comfort standard as reflected by the increase in the neutral temperature. Compared to the baseline case, the neutral temperature in the insulated and centrally heated dwellings was higher by $0.63^{\circ} \mathrm{C}\left(95 \% \mathrm{Cl}: 0.31^{\circ} \mathrm{C}, 0.95^{\circ} \mathrm{C}\right)$ and in the centrally heated only dwellings by $0.36^{\circ} \mathrm{C}$ (95\% $\left.\mathrm{Cl}:-0.02^{\circ} \mathrm{C}, 0.74^{\circ} \mathrm{C}\right)$.

The rise in the neutral temperature with increasing energy efficiency measure could partly be explained by the 'take-off' effect of clothing which level when compared to the baseline case was lower by 0.07 clo $(95 \% \mathrm{Cl}:-0.09,-0.05)$, i.e. insulation level almost 
equivalent to that provided by a T-shirt, in the insulated and centrally heated dwellings followed by centrally heated only dwellings which was lower by $0.04 \mathrm{clo}(95 \% \mathrm{Cl}:-0.07$, $-0.02)$ followed by insulated only dwellings which was lower by 0.03 clo $(95 \% \mathrm{Cl}:-0.06$, 0.00). The take-off effect demonstrates that improved energy efficiency seems to encourage householders to seek increased physical comfort through less clothing perhaps induced by the psychological comfort of having a reliable heating system and reduced fuel cost. Improved distribution of warmth throughout the house is also likely to result in the take-off due to occupants' clothing no longer reflecting the former cooler condition of the less well heated parts of the dwelling before the retrofit.

The rise in the neutral temperature could also be the result of the psychological expectation of increased comfort condition in centrally heated dwellings. For instance, the higher neutral temperature (not shown) observed in the living room $\left(19.4^{\circ} \mathrm{C}, \mathrm{SD}\right.$ : $\left.2.0^{\circ} \mathrm{C}\right)$ than in the bedroom $\left(18.0^{\circ} \mathrm{C}, \mathrm{SD}: 2.3^{\circ} \mathrm{C}\right)$ and in the evening $\left(19.3^{\circ} \mathrm{C}, \mathrm{SD}: 2.1^{\circ} \mathrm{C}\right)$ than in the morning $\left(18.4^{\circ} \mathrm{C}, \mathrm{SD}: 2.1^{\circ} \mathrm{C}\right)$ may suggest a process of mental association of warmer temperatures with rooms and situations that are traditionally better heated. Activity or clothing could not explain the higher neutral temperature in the evening since higher mean activity level was observed in the evening (1.41met, SD: 0.22 met) than in the morning (1.28 met, SD: 0.23 met) while no significant difference in the clothing condition was found (am: 0.78 clo, SD: 0.16 clo; pm: 0.78 clo, SD: 0.15 clo). Similarly, the activity and the clothing levels could not explain the difference in the neutral temperature between the two rooms since their comfort assessments were made at the same time.

\subsection{Comfort Vote versus Predicted Mean Vote}

$18.9^{\circ} \mathrm{C}$ was found to be the average Warm Front neutral temperature whereas a higher level of $20.4^{\circ} \mathrm{C}$ was predicted by PMV (Fig. 3). A temperature difference of $1.5^{\circ} \mathrm{C}$ 
represents space heating fuel savings in the range of $6 \%-10 \%$ [31] which is a significant amount when projected at a national scale. The higher PMV predicted neutral temperature may explain the origin of $21^{\circ} \mathrm{C}$ as the minimum indoor temperature recommended by the World Health Organisation (WHO) for the aged and the young [32] and also the minimum demand temperature (thermostat temperature) for which the UK dwellings are currently designed and energy rated in domestic energy models such as BREDEM [33].

One reason for the lower $\mathrm{CV}$ predicted neutral temperature could be due to acclimatization to cooler environment by the Warm Front households. This is because the average indoor temperature of the Warm Front dwellings prior to the intervention was $18.3^{\circ} \mathrm{C}\left(\mathrm{SD} 2.4^{\circ} \mathrm{C}\right)$ in the living room and $15.9^{\circ} \mathrm{C}\left(\mathrm{SD} 2.8^{\circ} \mathrm{C}\right)$ in the bedroom, levels much lower than the mean internal temperature of $19.1^{\circ} \mathrm{C}$ found in English dwellings in 2001 [34]. The Warm Front occupants with cool temperature history may find even a slight increase in the indoor temperature as feeling comfortable [35].

Acclimatization to the external weather condition, on the other hand, is not considered to be an explanatory factor for the lower neutral temperature in Warm Front dwellings as supported by the lack of statistically significant relationship between the two (section 7.7). The main reason is thought to be the conditioned nature of the Warm Front dwellings although it was originally suspected that their low energy efficiency would have lent them sensitive to the outdoor condition. The clothing habit, which often functions as the causal link between indoor thermal comfort and the outdoor weather, is not likely to be a significant link to the outside condition in this study since clothing decisions by the Warm Front householders were not likely to have been dictated by the weather, when considering the vulnerable nature of the householders [36]. 
The lower neutral temperature could also be explained by the householders associating cooler temperatures with qualities such as healthy lifestyle and better air quality. Interviews have revealed householders associating warmer conditions with increased 'stuffiness' which was in turn thought to cause or reinforce asthma [29]. This association may be due to increased irritation of the mucus membrane from dryer condition following the Warm Front upgrade [22].

The lower neutral temperature may also be due to a greater thermal tolerance from being in a home environment where the occupants can easily adapt their posture or clothing to attain comfort. This may also explain why the PMV index is found to be less effective in predicting thermal comfort in the Warm Front dwellings where the thermal comfort range could be wider than that in an office type environment where occupants have limited control over personal comfort $[8,19,37]$.

Since many Warm Front households had less than a year of settling in period following the upgrade, a revisit study investigating the long-term impact could reveal an increase in the neutral temperature over time. On the other hand, the post-Warm Front living room neutral temperature of $19.7^{\circ} \mathrm{C}\left(\mathrm{SD} 2.2^{\circ} \mathrm{C}\right)$ is remarkably close to the findings of the English House Condition Survey (EHCS) where the average temperatures judged by the residents to be 'comfortable' (EHCS 1991) [38] and 'about right' (EHCS 1996) [39] was $19.4^{\circ} \mathrm{C}$ for the living room suggesting that saturation in comfort demand may have been achieved in the post-Warm Front dwellings. Also evidence from a longitudinal survey of household temperature undertaken in 15 well-insulated and gas centrally heated dwellings in Milton Keynes Energy Park in England revealed no significant change in the internal temperature after a 16 year period supporting the possibility that the post-Warm Front household temperature may also see little change 
into the future [40].

The difference between the $\mathrm{CV}$ and the PMV indices can also be attributed to the quality of the input variables used in the PMV model. The decision to use the striptemperature which on average was found to be $0.3^{\circ} \mathrm{C}$ lower than the loggertemperature could partly explain the lower PMV index. The use of computer simulation to predict the mean radiant temperature and the simplified method used to record the clothing and the activity levels are also potential sources of error [41]. On the other hand, these limitations highlight the difficulty in guaranteeing a robust performance of the PMV model outside laboratory conditions and particularly when dealing with a large sample size as in the Warm Front study. A validation study on a sub-sample of dwellings to assess the accuracy of the estimated variables such as the mean radiant temperature and air velocity would have been useful in assessing the accuracy of the PMV prediction but such study was not carried out in this study.

\subsection{Conclusion}

This study analyzed the impact of the Warm Front energy efficiency scheme on domestic thermal comfort based on field-surveyed data collected from a large sample of low-income households in England. This study is unique in that few thermal comfort studies in the past have focused on the domestic condition in winter. The evidence shows that the introduction of insulation and central heating leads to increased indoor temperature and improved thermal comfort clearly demonstrating the process of take-back which explains why no reduction in energy consumption was observed following the Warm Front improvement [20]. The take-back process is the result of the combined effect of improved building fabric thermal performance - mainly associated with insulation - and occupancy behaviour demanding increased temperature for thermal comfort and less clothing for physical comfort - mainly associated with central 
heating. The combination of both insulation and central heating was found to be most effective in attaining the desired thermal comfort condition despite the associated increase in the neutral temperature. For the same temperature range, the PMV index was found to under-predict the actual thermal comfort condition and consequently predicted a higher neutral temperature of $20.4^{\circ} \mathrm{C}$ compared to $18.9^{\circ} \mathrm{C}$ which the average Warm Front households found to be comfortable. Due to the specific socioeconomic characteristic of the Warm Front households, caution is required in extrapolating any conclusions to the general population. 


\section{Members of the Warm Front Study Group}

Bartlett School of Graduate Studies, University College London

$\begin{array}{ll}\text { lan Ridley } & \text { Lecturer } \\ \text { Tadj Oreszczyn } & \text { Professor } \\ \text { Sung H Hong } & \text { Research Fellow }\end{array}$

Sheffield Hallam University

$\begin{array}{ll}\text { Roger Critchley } & \text { Visiting Research Fellow } \\ \text { Janet Gilbertson } & \text { Research Fellow } \\ \text { Geoff Green } & \text { Professor of Urban Policy } \\ \text { Mike Grimsley } & \text { Senior Lecturer } \\ \text { Bernadette Stiell } & \text { Research Associate } \\ & \\ \text { London School of Hygiene \& Tropical Medicine } \\ \text { Ben Armstrong } & \text { Reader } \\ \text { Zaid Chalabi } & \text { Lecturer } \\ \text { Jack Dowie } & \text { Professor } \\ \text { Shakoor Hajat } & \text { Lecturer } \\ \text { Emma Hutchinson } & \text { Research Fellow } \\ \text { Megan Landon } & \text { Research Fellow } \\ \text { Wendy MacDowall } & \text { Research fellow } \\ \text { Maryjane Stevens } & \text { Consultant } \\ \text { Nicki Thorogood } & \text { Senior Lecturer } \\ \text { Paul Wilkinson } & \text { Senior Lecturer } \\ & \\ \text { National Centre for Social } & \text { Research } \\ \text { Richard Boreham } & \text { Research Director }\end{array}$

\section{Acknowledgements}

This study was undertaken as part of the national evaluation of the Warm Front Scheme (England's home energy efficiency scheme). It was supported by the Department for Environment, Food and Rural Affairs (defra) and the Welsh Assembly Government under contract with the Energy Saving Trust (EST contract number M47). The views expressed in this paper are those of the authors and not necessarily those of the funding departments. 


\section{References}

[1] Moore R. The fall and rise of fuel prices and fuel poverty. National Energy Action 2005.

[2] Wilkinson P, Landon M, Armstrong B, Stevenson S, McKee M. Cold comfort: the social and environmental determinants of excess winter death in England, 19861996. Bristol: Joseph Rowntree Foundation; 2001.

[3] UK fuel poverty strategy. London: Department of Trade and Industry; 2001.

[4] Fuel poverty in England: the government's plan for action. Department for Environment, Food and Rural Affairs; 2004.

[5] Oreszczyn T, Hong, SH, Ridley I, Wilkinson P, The Warm Front Study Group. Determinants of winter indoor temperatures in low income households in England. Energy and Buildings 2006; 38:245-52.

[6] Henwood M, Fuel poverty, energy efficiency and health: a report to the EAGA Charitable Trust. Keswick, UK: EAGA-CT; 1997.

[7] Gilbertson J, Stevens M, Stiell B, Thorogood N. Home is where the hearth is: Grant recipients' views of England's Home Energy Efficiency Scheme (Warm Front). Social Science \& Medicine 2006; 63:946-56.

[8] ASHRAE Standard 55P. Thermal environmental conditions for human occupancy. Atlanta, USA: American Society of Heating, Refrigerating and Air-conditioning Engineers; 2003. 
[9] ISO Standard 7730. Moderate thermal environments - determination of the PMV and PPD Indices and specification of the conditions for thermal comfort. Geneva: International Organisation for Standardisation;1994.

[10] Fanger PO. Thermal comfort. Malabar, FL: Robert E. Krieger; 1982.

[11] de Dear RJ, Brager GS, Thermal comfort in naturally ventilated buildings: revisions to ASHRAE Standard 55. Energy and Buildings 2002; 34:549-61.

[12] Brager GS, de Dear RJ, Thermal adaptation in the built environment: a literature review, Energy and Buildings 1998;27:83-96.

[13] Nicol F, Thermal comfort: a handbook for field studies toward an adaptive model. UK: University of East London; 1993.

[14] Humphreys MA. The dependence of comfortable temperatures upon indoor and outdoor climates. In: Cena, Clarke, editors. Bionegineering, thermal physiology and comfort. London: Elsevier; 1978.

[15] Lovins AB, Air conditioning comfort: behavioral and cultural issues, e-source strategic issues paper. Boulder, CO: 1992.

[16] Davis Energy Group. Comfort reports - advanced comfort criteria, human comfort field studies. California Energy Commission; 2004.

[17] Schnieders J, Betschart W. Room air current in the passive house: measurement and simulation. HLH 03 2002:61.

[18] Rudge J, Winder R, Central heating installation for older, low income households: 
what difference does it make? In: Monterey proceedings of the indoor air. 2002. p. 1078-1083.

[19] Hunt D, Gidman M, A national field survey of house temperatures. Building and Environment 1982; 17(2): 107-24.

[20] Hong SH, Oreszczyn T, Ridley I, the Warm Front Study Group. The impact of energy efficient refurbishment on the space heating fuel consumption in English dwellings. Energy and Buildings 2006;38:1171-81.

[21] Hong SH, Ridley I, Oreszczyn T. The impact of energy efficient refurbishment on the airtightness in English dwellings. In: $25^{\text {th }}$ AIVC (Air Infiltration and Ventilation Centre) Conference, 15-17 September 2004. Prague, Czech Republic.

[22] Oreszczyn T, Ridley I, Hong SH, Wilkinson P, The Warm Front Study Group. Mould and winter indoor relative humidity in low income households in England. Indoor and Built Environment 2006;15(2):125-35.

[23] Håkan Nilsson, Department of Technology and Built Environment Laboratory of Ventilation and Air Quality, University of Gävle, INNOVA AirTech Instruments. Available from: <http://www.innova.dk/uploads/media/PMVcalc_v2_English.xls>.

[24] Humphreys MA, Nicol JF, An adaptive guideline for UK office temperatures, standards for thermal comfort: indoor air temperature standards for the $21^{\text {st }}$ century. Chapman \& Hall; 1995. p.190-5.

[25] CIBSE Guide A. Environmental design. London: The Chartered Institution of 
Building Services Engineers; 1999.

[26] Humphreys MA. Field studies of thermal comfort compared and applied. Building Services Engineer 1976;44:5-27.

[27] English house condition survey 2001. The Office of the Deputy Prime Minister; 2003.

[28] Collins KJ. Low indoor temperatures and morbidity in the elderly. Age and Ageing $1986 ; 15: 212-20$.

[29] Critchley R, Gilbertson J, Grimsley M, Green G, The Warm Front Study Group. Living in cold homes after heating improvements: evidence from Warm-Front, England's Home Energy Efficiency Scheme. Applied Energy 2007;84:147-58.

[30] Sanders C, Phillipson M. Review of differences between measured and theoretical energy savings for insulation measures. Centre for Research on Indoor Climate and Health, Glasgow Caledonian Unversity; 2006.

[31] Controls for domestic central heating and hot water. Energy efficiency best practice in housing. Guidance for specifiers and installers. Energy Saving Trust; 2003.

[32] World Health Organization, The effects of the indoor housing climate on the health of the elderly. Graz: 1982.

[33] Anderson BR, Clark AJ, Baldwin R, Milbank NO. BREDEM - BRE Domestic Energy Model: background, philosophy and description. Garston: Building 
Research Establishment; 1985. p. 18-22.

[34] Shorrock LD, Utley JI. Domestic energy fact file 2003. Watford: Building Research Establishment; 2003.

[35] Chun C, Kwok A, Mitamura T, Miwa N, Tamura A. Thermal diary: connecting temperature history to indoor comfort. Building and Environment 2008;43:877-85.

[36] Morgan CA, de Dear RJ, Brager G. Climate, clothing and adaptation in the built environment. In: Monterey proceedings of the indoor air. 2002. p. 98-103.

[37] Rowe DM, Lambert WG, Wilke SE. Pale green, simple and user friendly: occupant perceptions of thermal comfort in office buildings. In: Nicol, Humphreys, Sykes, Road, editors. Standards for thermal comfort. London: E and FN Spon; 1995. p. 59-69.

[38] English house condition survey 1991: energy report. London: Department of the Environment, HMSO; 1996.

[39] English house condition survey 1996: energy report. London: Department of Environment, Transport and the Regions, HMSO; 2000.

[40] Summerfield AJ, Lowe RJ, Bruhns HR, Caeiro JA, Steadman JP, Oreszczyn T. Milton Keynes energy park revisited: changes in internal temperatures and energy usage. Energy and Buildings 2007;39:783-91.

[41] Humphreys MA, Nicol JF. The validity of ISO-PMV for predicting comfort votes in every-day thermal environments. Energy and Buildings 2002;34:667-84. 